\title{
LA CONTRIBUCIÓN DEL PAISAJE VISUAL EN LA GENERACIÓN DE MARCAS TERRITORIALES
}

\author{
Joan Nogué \\ Departamento de Geografía. Universitat de Girona \\ joan.nogue@udg.edu \\ Jordi de San Eugenio Vela \\ Departamento de Comunicación. Universitat de Vic-Universitat Central de Catalunya \\ jordi.saneugenio@uvic.cat
}

\section{RESUMEN}

El paisaje ha sido y sigue siendo un elemento de primer orden en la representatividad física y simbólica del territorio. En los últimos tiempos, los procesos de promoción de los lugares han experimentado una profesionalización de las estrategias de creación de relatos territoriales habitualmente asociados a imaginarios paisajísticos. Este artículo pretende situar el actual consumo visual de paisajes en el marco de las nuevas estrategias de promoción y/o dinamización económica del territorio, que tienen en la generación de marcas de territorio a uno de sus más claros ejemplos. Con tal fin, se propondrá, mediante una extensa revisión crítica de la literatura vinculada a paisaje visual y marcas de lugares, una aproximación tentativa e inicial hacia una 'nueva' economía territorial, que tiene en el paisaje visual y en el branding territorial a dos de sus pilares fundamentales. En este marco de consumo simbólico de lugares, se aportarán algunas evidencias preliminares sobre el papel relevante que desempeña el paisaje y su capacidad de evocación simbólica para la generación de imaginarios geográficos proyectados a través de marcas asociadas a distintos lugares.

Palabras clave: Paisaje visual, marcas de lugar, identidad territorial, paisaje simbólico, consumo territorial.

Fecha de recepción: septiembre 2015.

Fecha de aceptación: septiembre 2016. 


\section{ABSTRACT}

The landscape has been and remains a critical element in the physical and symbolic representation of the territory. In recent times, the processes of place promotion have experienced a professionalization of its strategies through the creation of stories usually associated with landscape imaginary. This article aims to analyse the current visual consumption of landscapes in the framework of the new promotion strategies and/or economic revitalization of the territory, which have in generating place brands one of its clearest examples. For this purpose, it will be proposed through an extensive and critical review of the literature related to visual landscape and place brands, a tentative and initial approach towards territorial 'new' economy, which has in the visual landscape and the place branding two of its most important elements. Within this framework of symbolic consumption of places, some preliminary evidence on the important role of the landscape and its capacity for generating geographical imaginary projected through place brands will be provided.

Keywords: Visual landscape, place brands, territorial identity, symbolic landscape, place consumption.

\section{INTRODUCCIÓN}

De acuerdo con Harvey (1989), la época posmoderna se caracteriza por una compresión del espacio y el tiempo que ha provocado, entre otros efectos, la aceleración de la producción y el consumo de mercancías. Ello favorece la satisfacción instantánea de nuevas necesidades efímeras de consumo y contribuye a que la imagen se transforme en una mercancía que ofrece una salida fidedigna a gran parte de los renovados deseos de compra-venta de productos, servicios y territorios. Nos situamos, de este modo, ante la construcción de nuevos sistemas de signos e imágenes que son inseparables de la condición posmoderna (Harvey, 1989; Lash y Urry, 1994; Appadurai, 1996).

En el contexto que se acaba de describir, la imagen de los lugares se somete a un nuevo proceso productivo dictado por la lógica posmoderna, en la que la marca y su capacidad para representar identidades territoriales resulta clave en un renovado proceso de competencia entre espacios geográficos (De Uña y Villarino, 2011; San Eugenio, 2013). La marca de territorio, por tanto, se ocupa de proyectar la singularidad de los lugares con el fin de competir en un nuevo mercado de servicios que va más allá del turismo, y que enfatiza el consumo de espacios a priori (imágenes) por delante del propio consumo in situ (espacios físicos). Por tanto, la proyección de imágenes consumibles de lugares mediante la gestión de marcas territoriales es una de las realidades más significativas en el renovado proceso de comercialización de geografías (tangibles e intangibles) propio de la era posmoderna. Es por ello que la mutación de espacio (sin simbolismos específicos) a lugar (imbuido de determinados valores y/o atributos y, por tanto, de significados) se produce siguiendo las lógicas incentivadoras de la captación de capital (Kotler y Gertner, 2002; Goodman et al., 2010).

Por todo lo expuesto, se puede determinar que surge algo parecido a una ingeniería de imágenes espaciales, una 'autenticidad representada' en términos de MacCannell (1999), que deviene paradigmática en el consumo posmoderno de lugares y que, además, acaba 
condicionando la propia geografía de los espacios reales (Sack, 1992). En esta línea, Chatzikadis (2014) analiza el ejemplo de Atenas para ilustrar de qué forma la capital griega experimenta una transición fallida de la 'ciudad antigua' a la 'ciudad de consumo', donde lo importante no es únicamente qué consumes, sino dónde lo consumes. La transformación de Atenas en un gran 'oasis para el consumo' con motivo de los Juegos Olímpicos de 2004 provoca una nueva estratificación de clase resultado, en parte, de nuevas prácticas consumistas (elitistas) del ciudadano-consumidor neoliberal. En consecuencia, la ciudad experimenta un profundo cambio cultural (Chatzikadis, 2014, p. 34).

Asimismo, el recurso continuado a la estética, al dominio de la imagen sobre la narrativa, la transitoriedad y la fragmentación delimitan las coordenadas experienciales del tiempo y el espacio, lo que justifica, en gran medida, la consideración de lo posmoderno como una condición histórica y geográfica concreta (Harvey, 1989). De acuerdo con Soja (1989) y Beck et al. (1994), las dos características principales de la condición posmoderna radican en la continua búsqueda de capital simbólico, así como en el despliegue de una amplia producción cultural y de marketing. Ello nos traslada al análisis de la denominada 'economía del simbolismo', también denominada por algunos autores como 'economía de la imagen’ (MacCannell y MacCannell, 1982; Schroeder, 2004; Bauman, 2007). En el contexto descrito, el surgimiento del place branding se entiende como una posible respuesta a la necesidad de impregnar a los espacios de la posmodernidad de 'simbologías consumibles' (Hankinson, 2004; Kavaratzis, 2005; Govers y Go, 2009).

En el marco de este trabajo se plantea como objetivo principal el proponer, de forma inicial, exploratoria y tentativa, un constructo teórico relacionado con el actual consumo visual de paisaje (tangible e intangible) a modo de elemento físico y simbólico clave para la representación y la evocación territorial, así como para el despliegue de cualquier estrategia de branding de lugares ${ }^{1}$. En definitiva, se propone construir un argumentario que respalde lo que en este trabajo se denominará como landscape branding ${ }^{2}$.

Interesa delimitar, por tanto, el valor del paisaje como construcción social y cultural, y es por ello que merecerá especial atención el análisis específico de su capacidad de evocación visual y/o estética en el contexto de una estrategia general de construcción de marca de espacios geográficos. Muchos son los autores que señalan el papel preponderante del paisaje en la generación de simbologías y significados territoriales (Tuan, 1979; Daniel, 2001; Moya, 2011; Domosh, 2013). Sin embargo, son pocos los estudios que se han centrado en la elaboración de una posible teoría que recoja las posibilidades de representación competitiva del espacio geográfico a través del paisaje, especialmente en el marco actual del branding de lugares ${ }^{3}$.

1 Se ocupa de crear una identidad de marca estratégica a partir del principal capital activo del lugar (la identidad) para, posteriormente, situarlo en el mercado mediante la optimización de su principal valor pasivo (la imagen). La práctica del 'branding' de lugares debe partir de tres supuestos fundamentales: la identidad del lugar, la imagen del lugar y la experiencia de consumo con el lugar (Govers y Go, 2009).

2 Construcción y posterior proyección de marcas territoriales en base al poder de evocación visual del paisaje.

3 En cualquier caso, no debe confundirse nuestra propuesta de landscape branding, entendida como la generación de marcas territoriales a partir de un paisaje, con el término brandscape, que se corresponde con un neologismo del marketing que combina el concepto brand con landscape para referirse a un gran espacio de consumo de marcas, esto es, la demarcación del territorio en función de un determinado consumo de marcas (Murakami y Ball, 2013). Una vez más, nos encontramos con la dicotomía de consumo de marcas en el espacio (brandscape) versus el consumo del propio espacio -o más específicamente, del paisaje- a modo de marcas (landscape branding). 
Con el fin de desarrollar un corpus argumental que permita sustentar una teoría para branding de paisajes en base a su consumo visual, hemos recurrido a una extensa revisión crítica de la literatura directamente relacionada con el valor visual y/o estético del paisaje, así como a la literatura vinculada a las marcas territoriales.

En lo referido a los contenidos, el artículo se inicia con una reflexión sobre la generación de circuitos de valor a partir del consumo visual del paisaje y el papel que en este proceso desempeñan los imaginarios paisajísticos. A continuación, se presentan las características propias del 'nuevo' consumo simbólico de territorios, en el que las estrategias de place branding devienen críticas para el consumo en y de espacios, en base a una renovada distinción y proyección de imágenes asociadas a lugares. En este punto, el texto se va a ocupar, específicamente, de definir el rol del branding territorial a modo de importante y actual estrategia de aprovechamiento del imaginario geográfico en aras de generar nuevas economías territoriales. Seguidamente, el texto versará sobre un análisis del vigente consumo visual de paisaje, en el cual se mostrarán un conjunto de apuntes que expongan de qué forma el paisaje continúa siendo un elemento de evocación territorial de primer orden, a partir del cual se propondrá una teoría inicial para landscape branding. El artículo se cerrará con las pertinentes conclusiones.

\section{LA GENERACIÓN DE CIRCUITOS DE VALOR A PARTIR DEL ACTUAL CONSUMO VISUAL DE PAISAJE}

Con los años, el paisaje ha sido objeto de muchas definiciones desde diferentes disciplinas. En todos los casos, y en base a una mirada claramente geográfica, el llamado "paisaje simbólico" ha representado un campo recurrente de estudio, estrechamente ligado a su capacidad para generar un imaginario social (imaginabilidad geográfica), así como al desempeño de un papel fundamental en la generación de un "sentido de lugar" (Backhaus, 2009). Así, para Mitchell (2002, p. 384) "la representación del paisaje es siempre ideológica, a todas luces cargada de significado". Para Tuan (1979, p 90), el paisaje "aparece ante nosotros a través del esfuerzo que la imaginación ejerce sobre los datos que captan nuestros sentidos". Para Cosgrove (1985, p. 55) "es un modo de ver, una composición y una estructuración del mundo para que pueda ser apropiada individualmente, una ilusión de orden y control ofrecida al espectador a través de la composición de espacio", y, de acuerdo con Cosgrove y Daniels, (1988, p.1) se trata de "una imagen cultural, una forma pictórica de representar, estructurar o simbolizar el entorno". Por último, y de acuerdo con Campelo (2015, p. 56): "el paisaje es una construcción social y cultural significativa, que permite una conexión y una mediación directa en las relaciones que se establecen entre las personas y el entorno físico. Es a través del paisaje que las personas experimentan el lugar". De hecho, el paisaje representa una categoría espacial única en geografía (Rose, 2002), entre otras razones, por su enorme relevancia en el proceso de creación de imaginarios.

En efecto, existe una extensa literatura sobre la formación de imaginarios paisajísticos, entendiendo por imaginario no sólo 'las imágenes de', sino la creación continua e indeterminada de formas e imágenes que no sólo remiten a 'lo real', sino también a lo percibido (Castoriadis, 1985). El concepto de imaginario se refiere a una creación incesante de figuras, formas e imágenes a partir de las cuales solamente puede uno referirse a algo. Lo imaginario está relacionado con procesos cognitivos y de memoria, sin olvidar sus expresiones propia- 
mente materiales, y se manifiesta tanto a nivel individual como colectivo. En este último supuesto, "los modelos de imaginarios sociales pueden entonces ser entendidos como fuerzas transversales en el pensamiento social, que imprimen una direccionalidad sólida hacia ciertos comportamientos colectivos" (Hiernaux, 2006, p. 30).

En la actualidad, las estrategias de marcas territoriales desarrollan un papel muy importante en la composición de imaginarios de paisaje (Campelo, 2015). No es nuevo el uso de imágenes de lugares en el ámbito del marketing y/o branding. Lo realmente novedoso es el establecimiento de mecanismos de control y/o apropiación de la mirada hacia un paisaje, la inducción de imaginarios de paisaje; en definitiva, el control del frame 4 (Hansen y Machin, 2013; Porter, 2016). Ello nos sitúa plenamente en el análisis de la relación existente entre la construcción social del paisaje y su reproducción económica y conlleva la puesta en valor de paisajes hasta el momento poco valorados por la población local; es decir, la dotación de 'legibilidad' y 'visibilidad' a paisajes que ya estaban ahí, pero que, o nunca habían formado parte del imaginario colectivo, o habían huido de él. En cualquier caso, la actual gestión de los imaginarios de paisaje, la interrelación entre percepción e imaginación o la producción de significados espaciales, entre otros, nos trasladan al concepto de 'geografía del símbolo' (Backaus, 2009), algo próximo a lo que Rose (2002) y Wylie (2007) denominan como ‘geografía de la representación', esto es, la generación de formaciones cognitivas de tipo socio-cultural.

En cualquier caso, el estudio del paisaje simbólico se ha asociado habitualmente con la geografía cultural, históricamente interesada por los procesos de producción social del paisaje. La investigación sobre el paisaje material (medio físico) y el paisaje estético (imágenes visuales) ha ocupado una gran cantidad de estudios, tanto convencionales como más innovadores (Rose, 2002). Ambos coinciden, eso sí, en señalar que el paisaje representa la transformación de una imagen espacial efímera en un entorno estable, socialmente construido (Sauer, 1925; Cosgrove, 1984; Duncan y Duncan, 1988; Jackson, 1989). Asimismo, Backhaus (2009) mantiene la existencia de dos concepciones fundamentales para el análisis del paisaje: por un lado, el "sentido ordinario del paisaje" (a modo de extensión territorial), tal como se muestra en nuestros encuentros cotidianos; y, por el otro, los "paisajes simbólicos", que son culturalmente codificados con atributos que representan algo más que los significados de vinculación pragmática cotidiana.

En los últimos años, el paisaje simbólico y la proyección de sus valores culturales han sido ampliamente "explotados" por la publicidad, el marketing y el branding (Nogué y San Eugenio, 2011; Maruani y Amit-Cohen, 2013). Se trata de técnicas que utilizan repetidamente el valor inmaterial de los lugares para generar valor de marca de productos y/o servicios. De esta forma, el paisaje deviene una construcción simbólica de primer orden, un "escaparate" fundamental para el posicionamiento de países, ciudades o regiones en un mercado global de lugares. Básicamente, todo ello tiene lugar a través del consumo visual (Daniel, 2001; Matless, 2003).

Así, parece indudable la existencia de implicaciones geo-económicas en lo referido a la generación de circuitos de valor y sentido en base a estrategias de marketing y branding de lugares, aunque, como sostiene Pike (2013,p. 317), "las dimensiones geográfico-económicas

4 Término inglés que se traduce por fotograma, esto es, cada una de las imágenes instantáneas en las que se divide una película de cine que dan sensación de movimiento al ser proyectadas secuencialmente (Konigsberg, 2004, p. 235). 
de las marcas carecen de claridad conceptual y actualmente están insuficientemente estudiadas". En este sentido, este estudio propone una aproximación tentativa a las geografías del consumo de lugares, a través de la gestión de marcas (place branding) y en base a la contribución nuclear del paisaje visual en la generación de imaginarios territoriales. De igual forma, el consumo aplicado a los circuitos espaciales representa un tema emergente en la geografía económica (Aoyama, Murphy y Hanson, 2011). En cualquier caso, es indudable la contribución del paisaje para la construcción de un "sentido de lugar", punto de partida para el actual desarrollo de marcas de lugar (Campelo, 2015).

\section{EL 'NUEVO’ CONSUMO SIMBÓLICO DE LUGARES}

Para empezar, deberíamos definir el término 'consumo'. De acuerdo con Mullins et al. (1999, p. 46-47), “el consumo se refiere al proceso mediante el cual las personas adquieren y utilizan bienes y servicios para la supervivencia y la reproducción biológica y social, y ahora, cada vez más, con fines expresivos, así como para la diversión y el disfrute”. En el ámbito de los espacios, el consumo experimenta una clara emergencia y un continuo desarrollo como respuesta al creciente poder de consumo de los ciudadanos. Se impone, en este sentido, una nueva 'ideología cultural de consumo', algo semejante a un imperativo cultural que señala la necesidad de consumo del máximo número de bienes, servicios y lugares posible. Se experimenta, en este sentido, una renovada tendencia de consumo visual (a través de imágenes) destinada a poseer, conquistar o bien colonizar a 'nuevas' geografías transformadas en bienes transaccionales (Urry, 2002; Bauman, 2007; Anholt, 2010). Hablamos, en definitiva, del place-product, o bien de la difícil conceptualización del lugar como producto consumible (Medway y Warnaby, 2008; Warnaby, 2009; Warnaby y Medway, 2013).

En cualquier caso, el consumo tiene una naturaleza indudablemente espacial (Pike, 2009; Goodman et al., 2010), que requiere de un contexto geográfico que lo envuelva (Lefebvre, 1991). En este sentido, las geografías del consumo han sido objeto de estudio por parte de diversos autores (Mullins et al., 1999; Henderson, 2009; Mansvelt, 2010; Overton, 2010), si bien en este trabajo interesa explorar, específicamente, las denominadas 'geografías consumibles'. Ello nos lleva a delimitar dos grandes tipologías de trabajo en la relación dual que se establece entre consumo y lugar. Por un lado, cabe destacar el consumo que se produce en un entorno espacial: nos referimos al 'consumo en el lugar', también denominado 'consumo literal' por parte de Urry (1995). Tiene relación con el consumo de bienes y/o servicios en un entorno territorial concreto. Este concepto lo ha trabajo exhaustivamente Pike (2009, p. 639) en el marco del actual branding comercial, asegurando que "los procesos de definición de marca se vinculan, ineludiblemente, a asociaciones espaciales".

Por otro lado, existe el consumo de espacios y/o lugares, o bien 'consumo simbólico', según Urry (1995). La 'comercialización geográfica' ha sido también tratada extensamente por la literatura especializada, especialmente en el ámbito de la geografía humana (Agnew, 2005; Massey, 2005; Gregory, 2009; Nogué, 2009). En este punto, cabe referirse al proceso de compra-venta de geografías, y por tanto, a los procesos de consumo directo y/o mediado de espacios geográficos, íntimamente vinculados a renovadas estrategias de promoción y/o comercialización del paisaje y a su capacidad para generar proyecciones e imaginarios territoriales, que deviene el objeto de estudio principal de este artículo. 
En el contexto del consumo de lugares, Rakić y Chambers (2012) sugieren la emergencia de una nueva tendencia denominada place embodiment, que implica el replanteamiento de la forma mediante la cual los ciudadanos viven, consumen y, en definitiva, se imbuyen de sus espacios geográficos, depositando un mayor énfasis en el proceso de construcción social de los lugares en base a aspectos sensoriales (vista, oído, tacto, olfato y gusto), afectivos (emocionales) y cognitivos (mentales). En la misma línea se pronuncian Cheng y Kuo (2015), cuando destacan la importancia del denominado place boding, esto es, la forma mediante la cual los individuos establecen vínculos afectivos y/o emocionales con los lugares y, más específicamente, con el paisaje. Es lo que Murakami y Ball (2013) denominan como 'economía afectiva'.

De igual forma, la transformación de lugares en espacios de consumo se concreta, siguiendo a Sack (1992), en la metamorfosis de unas determinadas localizaciones convertidas en anuncios. Es el caso, entre otros espacios, de los grandes almacenes, galerías comerciales y parques temáticos, que el autor utiliza para ejemplificar la conversión de los lugares en artículos de consumo en masa. La aplicación a los espacios de las lógicas consumistas propias de la era posmoderna ha generado dos consecuencias fundamentales en los ámbitos físico y conceptual. En el ámbito físico, Sack (1992) coincide con la gran mayoría de teóricos del posmodernismo al señalar que el espacio se convierte en un simulacro, un barniz, un pastiche, una exaltación de lo inauténtico, caracterizado por una falta de sentido de lugar. En el ámbito conceptual, el consumidor cuestiona el sentido de ubicación y localización en el espacio que ha desarrollado tradicionalmente la geografía. En consecuencia, debe considerarse que los espacios mantienen unas relaciones estrechas con el consumo, no sólo por el hecho de habilitar un marco geográfico para unas prácticas de consumo determinadas, sino por el argumento que sustenta Sack (1992), cuando señala que el consumo deviene un excelente mecanismo creador y modificador de geografías.

De este modo, la nueva cultura de consumo propia de la etapa posmoderna sitúa a los espacios en las lógicas de circulación efímera de anhelos y deseos de las nuevas sociedades, con lo que los lugares se convierten, propiamente, en objetos de consumo. En este punto, los territorios comienzan a competir con objetivos que van más allá de la captación de turistas. Los niveles iniciales de información y promoción del territorio evolucionan hacia nuevos planteamientos que despierten la persuasión y la emoción del espacio, que tienen por objetivo principal la atracción de inversiones permanentes, principalmente a través de la comercialización de una imagen de marca (identidad) competitiva (Anholt, 2010).

\section{LA ECONOMÍA DEL IMAGINARIO TERRITORIAL}

Lash y Urry (1994) se refieren a la emergencia de una nueva economía de signos y espacios característica de la etapa posmoderna que sigue al capitalismo organizado. Se instala un nuevo tipo de acumulación, producción y consumo de naturaleza reflexiva, característica de una nueva era caracterizada por un capitalismo desorganizado. La reflexividad estética sitúa sus fundamentos en la acumulación de imágenes y símbolos expresivos, que se concreta en la actual producción y posterior consumo de imágenes territoriales, donde el marketing, y actualmente el branding, desempeñan un papel decisivo como industrias culturales líderes en la producción de artefactos estéticos. En este punto, el espacio geográfico adopta la categoría de alegórico o simbólico. 
Históricamente, el consumo de lugares se ha producido, esencialmente, a partir de procesos previos de comercialización del espacio geográfico. Inicialmente, se habló de la 'promoción territorial' con claras vinculaciones al turismo. Para Ward y Gold (1994), la promoción del territorio presenta tres áreas de interés. En primer lugar, se identifica la promoción a modo de comunicación de una determinada imagen. En segundo lugar, se relaciona con un ejercicio de vinculación a la política y a la gestión pública. En tercer y último lugar, se vincula la etapa final de la promoción del espacio geográfico con el inicio de la era del marketing territorial, que obedece a una práctica vinculada al ámbito corporativo que implica, al mismo tiempo, gestión y comunicación.

Ashworth y Voogd (1994) sostienen que la transición de la promoción al marketing de lugares se produce por la simple constatación de que la administración del territorio obedece a nuevas lógicas económicas y, por tanto, de mercado, y, en este sentido, en un entorno territorial cada vez más competitivo, se produce una aproximación consciente al marketing, no tanto como una posible solución a los problemas de ordenación del territorio, sino como una filosofía de gestión de los lugares. Por lo tanto, se tiende hacia una mercantilización de una selección de atributos de los lugares con el objetivo de proyectar una imagen positiva (Medway y Warnaby, 2008; Cànoves, Prat y Blanco, 2016).

Por último, la transición del marketing al branding de lugares tiene lugar, según Anholt (2010) y Govers (2011), por la necesidad de enfatizar la marca como dispositivo de diferenciación y posicionamiento de determinados lugares. La gestión de la imagen de espacios geográficos a diferentes escalas (países, regiones, ciudades, etc.) a partir de criterios propios de marcas corporativas, deviene una metáfora que permite entender de qué forma los territorios pueden competir más efectivamente en la era moderna. Govers y Go $(2009$, p. 17) definen el término place branding en su obra seminal sobre marcas en el ámbito geográfico: "Consiste en crear una identidad de marca estratégica basada en el principal valor activo de un lugar (la identidad), con un claro objetivo de posicionamiento, lo que, por ende, implica optimizar su valor pasivo principal (la imagen). De este modo, el desarrollo de marcas de lugar debe basarse en tres instancias fundamentales: la imagen e identidad del lugar, y la experiencia del consumidor en el lugar". En otras palabras, se trata de una estrategia que destile la esencia de los lugares mediante el uso de símbolos de fácil transmisión. Aun así, las fronteras que separan el marketing de lugares del place branding son actualmente muy difusas (Kavaratzis y Hatch, 2013).

El branding de lugares, en el contex to descrito, ejerce el rol de símbolo descodificador de una nueva legibilidad estética del territorio, además de añadir valor a las características de un espacio geográfico que busca proyectar unificadamente la acumulación de símbolos que lo singularizan. Es así como las marcas de territorio se identifican y se manifiestan plenamente integradas en esta nueva economía de símbolos y espacios tan propia del capitalismo tardío. En este sentido, Lash y Urry (1994) entienden las marcas como objetos culturales reflexivos, resultado de operaciones estéticas llevadas a cabo, entre otros medios, por agencias de marketing y publicidad. El traslado de la ya mencionada 'reflexividad estética' al ámbito de los espacios geográficos acaba provocando la actual proliferación de marcas territoriales. La marca de lugares escenifica, en consecuencia, la transformación del lugar en bien de consumo, sobrevenida por la industria económica y cultural que rige símbolos y espacios. La marca denota y evoca la carga simbólica y significante inherente a unas determinadas geografías. Por ello, la explotación de la marca se convierte en primordial en la connotación 
de imágenes propias del posmodernismo. La filiación semiótica de las sociedades, constituidas en forma de grandes descodificadores de simbolismos, encuentra en la marca a un instrumento de lectura de la imagen asociada a determinados lugares (San Eugenio, 2013).

\section{EL CONSUMO VISUAL DE PAISAJE}

Nogué (2009, p. 33) define el paisaje en los siguientes términos "El paisaje es, a la vez, una realidad física y la representación que culturalmente nos hacemos de ella; la fisonomía externa y visible de una determinada porción de la superficie terrestre y la percepción individual y social que genera; un tangible geográfico y su interpretación intangible. Es, también, el significado y el significante, el continente y el contenido, la realidad y la ficción, el original y la copia". Por su parte, la Convención Europea del Paisaje (CEP) define el paisaje como "un área, tal y como la percibe la población, el carácter de la cual es el resultado de la acción y la interacción de factores naturales y/o humanos" (Consejo de Europa, 2000).

De acuerdo con Tveit el al. (2006), Ode et al. (2008) y Domosh (2013), en el análisis de los aspectos visuales del paisaje existen dos tendencias mayoritarias. Por un lado, se considera la aproximación del experto, que sitúa el foco de atención en caracterizar el paisaje como objeto o sistema territorial, en determinar sus aspectos físicos, esencialmente cuantificables. Por otro lado, se impone la aproximación subjetivista, donde el interés radica en la experiencia del observador con el paisaje, enfatizando de este modo las características intangibles (simbólicas) vinculadas a la percepción individual, esto es, a la mirada que sobre el paisaje proyectan los individuos (Daniel, 2001; González y León, 2003; Nogué, 2009). Existe también un acuerdo generalizado para reconocer que el paisaje dispone de características propias que lo diferencian de otras variables territoriales o ambientales. Asimismo, se afirma que la percepción (juicio de valor) es el vehículo a través del cual una realidad física se transforma en paisaje (Tuan, 1974; Cosgrove, 1984; Berque, 1995; Bell, 1999).

Domosh (2013) se ha ocupado recientemente de estudiar las actuales tipologías de consumo de paisaje. En este sentido, sitúa en lugar preferente el consumo visual como máxima expresión de su poder de evocación simbólica y de significados. A continuación, incluye un exhaustivo apartado dedicado a discernir las formas actuales de comercialización del paisaje. En este punto, la autora destaca la transición del tradicional consumo en el paisaje (especialmente en el ámbito turístico) al renovado consumo de paisaje, esto es, "el empaquetado y posterior venta de paisajes por razones comerciales" (Domosh, 2013, p. 201). Aquí, los procesos de marketing y branding inspirados en la capacidad de evocación simbólica (de significados) del paisaje ejercen un papel muy destacado, aunque no aparezca el término landscape branding para denominarlos como tales.

Un elemento de reflexión interesante introducido por Domosh (2013) es el camino de ida y vuelta que supone la dualidad consumo-paisaje. De este modo, sostiene que el deseo de consumir geografías, acaba provocando la aparición de paisajes reales e imaginados. Serían buen ejemplo de ello los parques temáticos, las cada vez más habituales arquitecturas icónicas, los shopping malls o los holiday resorts. Asimismo, se produce un 'consumo literal' de paisajes que la autora (2013, p. 203-204) sitúa en la línea del 'consumo devorador del medio ambiente'. Por último, Domosh (2013) utiliza el término landscaping para referirse al paisaje como una forma propia de 'producción paisajística' para el consumo. La autora utiliza los ejemplos de 
creación de jardines privados en la antigua China por parte de élites académicas, instaurados con el fin de acceder directamente a sus hogares. Ello representa, en su conjunto, una 'producción genuina' de paisajes.

De Burgh-Woodman y Brace-Govan (2010) sostienen que la visión deviene el modo principal a través del cual los individuos conectan con sus respectivos entornos e interpretan sus experiencias de consumo en el actual mercado de lugares. Los mismos autores añaden lo siguiente (2010, p. 174): "Las imágenes de los lugares y sus significados inherentes, son especialmente elocuentes en comunicaciones de marketing y branding. En esta tesitura, la ventaja competitiva se obtiene mediante una conexión efectiva con los consumidores a través de la presentación visual de informaciones y significados (Schroeder, 2004).

La imagen es un elemento crítico en el actual capitalismo simbólico (Schroeder, 2002). En este punto, introducimos el concepto de visualidad de paisaje a partir del término visualidad inicialmente sugerido por De Burgh-Woodman y Brace-Govan (2010). Así, definiremos la visualidad del paisaje como la interrelación entre la perspectiva cultural y la subjetividad individual en el proceso de percepción y posterior descodificación del significado de un paisaje. Estamos hablando, en definitiva, del sentido de lugar, un concepto esencialmente geográfico (Massey, 2005).

Todo parece indicar que nos encontramos, más que nunca, en la era de la visión y la visualidad inducida. Internet, los smartphones, la fotografía digital, el blogging, las plataformas online de alojamiento de fotografías como Flickr, el universo social media (Instagram, Pinterest, etc.), las cámaras de fotos y video GoPro, los drones que filman imágenes aéreas o los vídeos obtenidos bajo el agua, escenifican el transcurso de nuestra vida relatado a través de capturas de vivencias transformadas en imágenes consumibles. Nuestra cultura actual es profundamente visual. Es por todo ello que hoy hablamos, con toda normalidad, de una economía de la imagen, de la atención, del signo, de la estética, o bien de la experiencia (Schroeder, 2004).

"El consumo visual empieza con imágenes" (Schroeder 2004: p. 230). De hecho, el mismo autor sugiere cuatro propuestas para abordar el estudio del consumo visual en la actual economía de la imagen: a) la publicidad es la fuerza dominante de la comunicación global; b) el universo fotográfico es condición indispensable para la percepción del mundo; c) la identidad es inconcebible sin fotografías; y por último, y quizá el punto más importante para nuestro trabajo, d) la imagen (visual) es fundamental para el branding de productos, servicios (y territorios).

Ahora que tenemos situados los conceptos de 'consumo visual' y 'consumo de paisaje', vamos a hablar de 'consumo visual de paisaje' como punto inicial para la construcción de una teoría para landscape branding. Ode et al. (2008) identifican nueve indicadores que definen el carácter visual del paisaje: complejidad, coherencia, perturbación, administración, imaginabilidad, visualidad, naturalidad, historicidad y efimeralidad. Para los intereses preferentes de este artículo, vamos a detenernos en el indicador imaginabilidad. Este atributo refleja, según Ode et al. (2008, p. 97) "la capacidad de un paisaje para crear una imagen visual impactante, esto es, distinguible y memorable". Para Lynch (1960, p. 9) la imaginabilidad es "la capacidad de un objeto físico para evocar una imagen fuerte en cualquier observador". Este concepto se relaciona con otros aspectos subjetivos y vivenciales asociados a la percepción del paisaje, como por ejemplo: espíritu del lugar (Bell, 1999), genius loci (Lynch, 1960), vividness (Litton, 1972) o topophilia (Tuan, 1974). Todos ellos, vinculados a la capacidad del 
paisaje para ofrecer un marco de interpretación de los lugares, para definir su esencia, para dotarlos de significado, para transformarlos, en definitiva, en espacios únicos y memorables.

Es lo más parecido a lo que en el ámbito del marketing o del branding se denomina habitualmente como 'estrategia de diferenciación' (en este caso a partir de una identidad paisajística singular) a partir de la construcción de un discurso de marca (quizás espontáneo, no premeditado) que nos sitúe, mediante la consecución de un previo posicionamiento, en un mercado global de lugares cada vez más competitivo. Parece indudable que el paisaje y su capacidad para construir un relato territorial, o bien para asignar significado a los lugares se ajusta, estrictamente, a lo que hoy entendemos como marca de lugar, definida por Olins (2003, p. 168) como "un dispositivo de gestión de percepciones que respalda los valores que distinguen a un lugar en comparación con otros lugares, que tiene por objetivo fundamental dar a conocer una identidad única para alcanzar un posicionamiento específico".

Asimismo, parece más fácil construir una teoría a partir de una evidencia real, práctica y aplicada. En otras palabras, creemos que el uso del paisaje ${ }^{5}$ con finalidades de construcción de marca territorial (landscape branding) es hoy una evidencia, una obviedad, especialmente manifiesta en los ámbitos del marketing y la publicidad (Maruani y Amit-Cohen, 2013). Entendemos que el esfuerzo de teorización para landscape branding resulta favorecido por la certeza, empíricamente demostrable, que señala que el paisaje es y ha sido, tradicional e históricamente, un valioso elemento de representación y proyección de identidades territoriales, ya sea de forma inducida (previa definición de una estrategia) o espontánea (percepción no mediada individuo-paisaje), a cualquier escala y bajo cualquier estrategia de comercialización del territorio (Urry, 2002; Nogué y San Eugenio, 2011; Domosh, 2013). Por tanto, en el ámbito de la promoción, el marketing y actualmente, el branding, el paisaje deviene un importante activo en la proyección de valores y/o atributos geográficos, un elemento indispensable para las renovadas necesidades de diferenciación y posicionamiento de los lugares. Ello nos sitúa directamente en la órbita de lo que pretendemos definir como landscape branding.

De igual forma, existen algunas evidencias más que ponen de relieve el valor del paisaje para la construcción de un relato, una narrativa o un place storytelling bajo las directrices estratégicas del branding: a) El espacio geográfico inmortalizado como resultado de una fotografía, de una grabación de imágenes o bien de cualquier captura de pantalla en Internet es un paisaje (humanizado o no); b) Ostenta el práctico monopolio en la representación y/o evocación visual del espacio geográfico; c) Es un indudable contenedor de significados y simbolismos asociados al espacio y al lugar. En otras palabras, el paisaje es paradigmático en la creación de un sentido de lugar; d) Deviene un elemento clave en la 'explotación' comercial del intangible geográfico (afectos, emociones, sensaciones, experiencias).

Únicamente con finalidades ilustrativas, y con el objetivo de aportar algunas evidencias que den buena muestra del rol que desempeña el paisaje visual en la generación de imaginarios y marcas territoriales, se ha recuperado la campaña de promoción turística 'La Rioja Apetece' impulsada por 'Turismo de la Rioja' (Gobierno de La Rioja) en junio de 2012 y reeditada hasta la actualidad ${ }^{6}$.

5 Especialmente en la generación de imaginarios territoriales en base a la proyección de un determinado paisaje visual.

6 Las imágenes que se muestran a continuación cuentan con el permiso explícito de reproducción de 'La Rioja Turismo' (Gobierno de La Rioja). 


\section{Figura 1}

UNIVERSO VISUAL CORRESPONDIENTE A LA CAMPAÑA PUBLICITARIA "LA RIOJAAPETECE" IMPULSADA POR TURISMO DE LA RIOJA (2016)

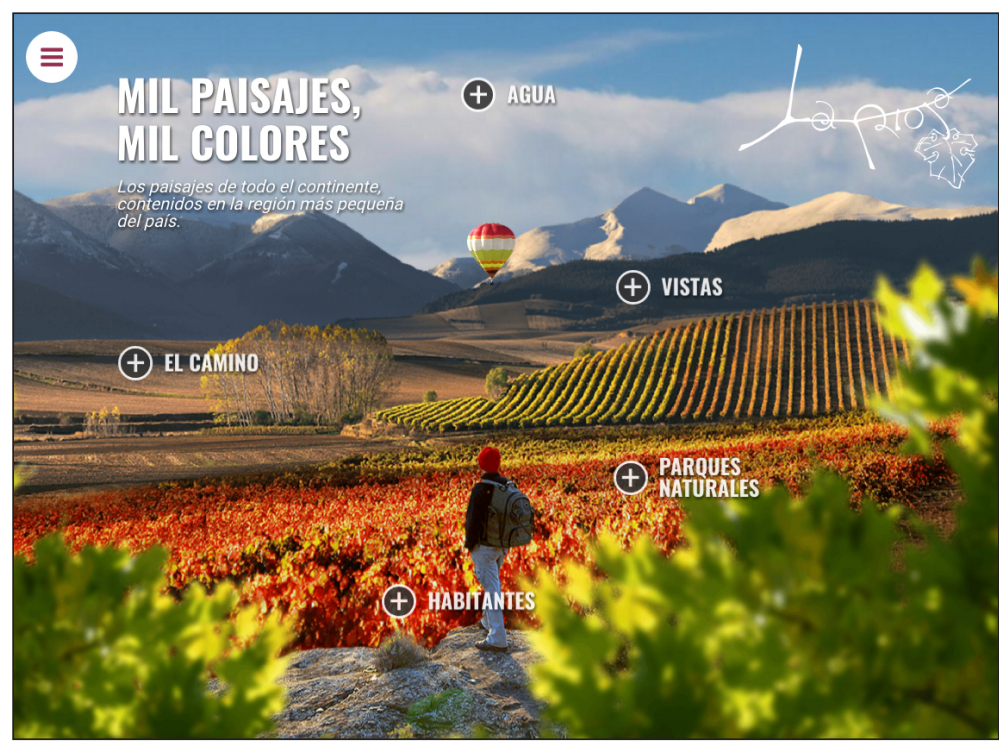

Fuente: http://lariojapetece.com/

Figura 2

UNIVERSO VISUAL CORRESPONDIENTE A LA CAMPAÑA PUBLICITARIA "LA RIOJA APETECE" IMPULSADA POR TURISMO DE LA RIOJA (2016)

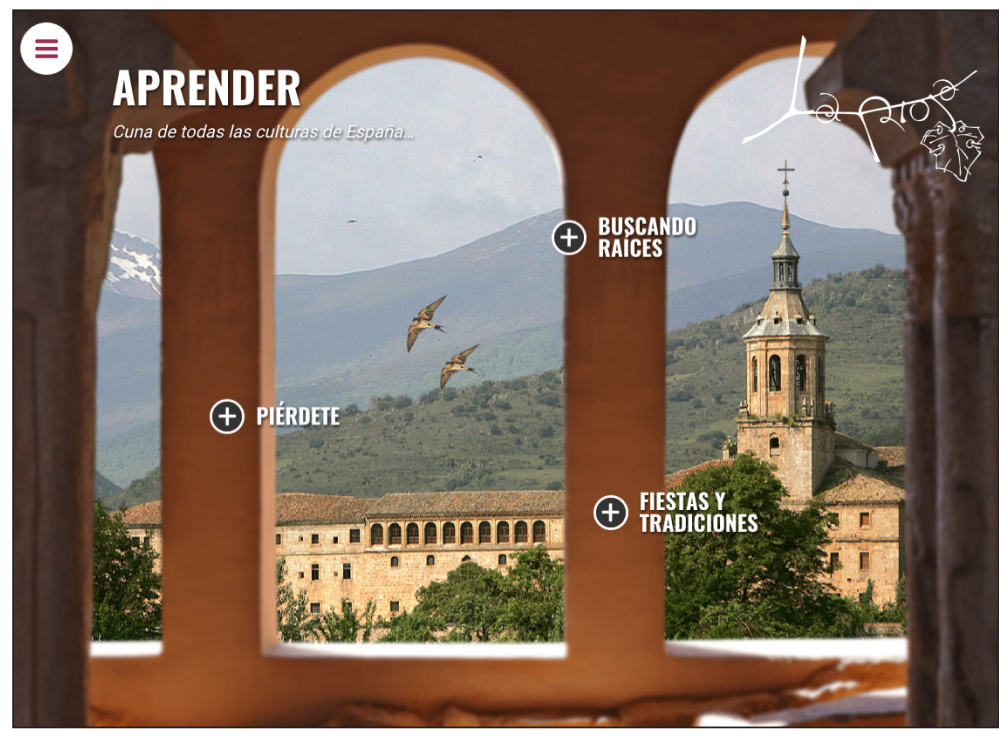

Fuente: http://lariojapetece.com/ 


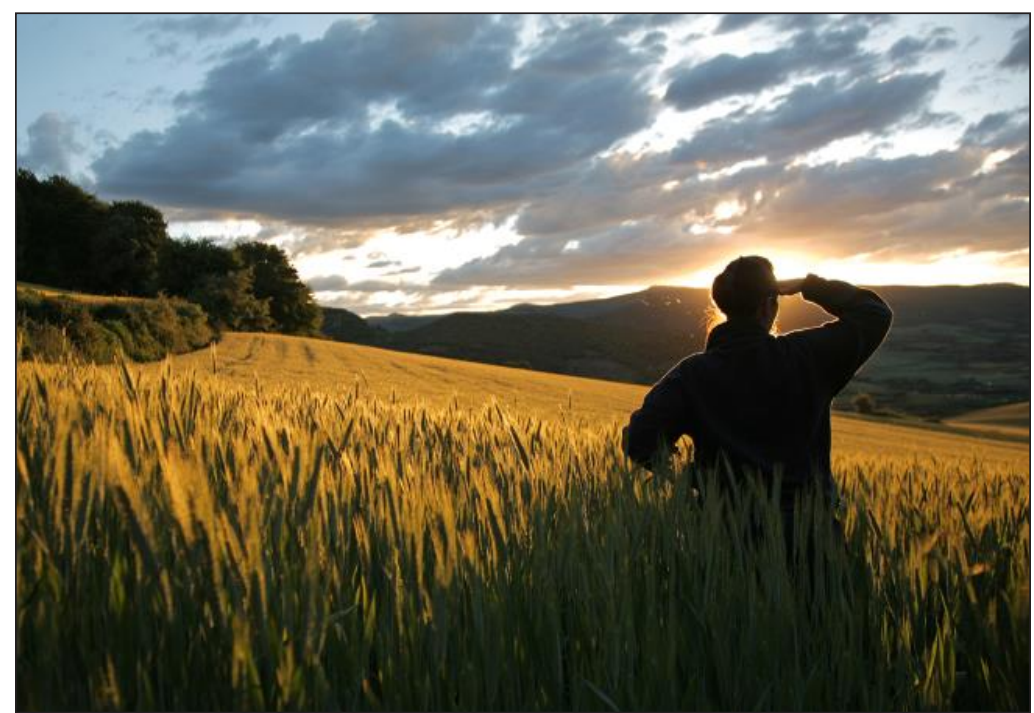

Fuente: https://lariojaturismo.com/comunidad/larioja

\section{CONCLUSIONES}

El paisaje ha sido y sigue siendo un elemento de primer orden en la representación física y simbólica del territorio y, hoy más que nunca, se utiliza en los procesos de promoción de los lugares, basados en la creación de relatos territoriales habitualmente asociados a imaginarios paisajísticos.

En este sentido, se hace indispensable el inicio de una línea de investigación que sea capaz de ofrecer una salida fiable a la emergente demanda de estudios que relacionen la creación y posterior proyección de marcas territoriales y el paisaje, en unos momentos en los que éste se ha convertido en una pieza clave de las nuevas políticas de ordenación del territorio, así como también en infinidad de debates suscitados en ámbitos sociales y culturales que apuestan por la aplicación de la filosofía que emana del Convenio europeo del paisaje. Y, en última instancia, esta línea de investigación es relevante también por otra razón, más social que académica: hay que aprender a distinguir cuándo y cómo se instrumentalizan nuestras emociones en relación con el paisaje. Y quién las instrumentaliza y para qué. A menudo, la incursión del marketing y/o branding en el ámbito de actuación de los lugares se ha concebido como una mera perpetuación de estereotipos más o menos simplistas y, más aún, como una simplificación nefasta de la complejidad geográfica (Porter, 2013 y 2016). Sin embargo, existen algunos estudios que apuntan el valor que, para la conservación de los valores del paisaje y la sensibilización ambiental, tiene la implementación de estrategias de place branding bien pensadas y diseñadas (Tobias y Müller, 2013; San Eugenio-Vela y Barniol, 2015). 
Por tanto, la novedad no radica en el uso ya conocido de recursos visuales de paisaje para la promoción de lugares, sino en la construcción cuidadosamente instrumentada de miradas, ángulos, representaciones, narrativas e interpretaciones propias del espacio geográfico que secuestran, de algún modo, la mirada espontánea hacia un determinado lugar. Todo está perfectamente premeditado. De acuerdo con ello, el paisaje visual representa un punto crítico en la forma de ver (y descodificar) la esencia de los lugares a través de una estrategia de marca de lugar. En este sentido, el place branding que tiene en el paisaje visual un argumento definitivo para la proyección de lugares, impone un nueva cultura de la mirada dirigida a los territorios y el paisaje, en base a un relato eminentemente visual a partir del cual hacer deseable a un determinado lugar, ya no únicamente con objetivos de promoción turística, sino con la intención de captar talento, infraestructuras e inversión, entre otros objetivos, de los que destacaríamos uno en particular, ya apuntado más arriba: generar un potente sentido de lugar entre la población que contribuya al empoderamiento de la misma y le dote de más y mejores instrumentos para el gobierno del territorio.

Se intuye, en esta tesitura, que la geografía dispone de una valiosa oportunidad en el estudio del enorme potencial comunicativo del paisaje, algo que el marketing y, más recientemente, el branding, tienen muy claro, y ello sin haber profundizado demasiado en el propio concepto de paisaje, como sí se ha hecho desde la geografía. Se debería ser consciente que, en el contexto de la contemporaneidad, el paisaje es uno de los conceptos geográficos con una dimensión comunicativa más notable, por lo que es utilizado una y otra vez en el proceso comunicativo de bienes, servicios y/o lugares, lo que confiere a la geografía como disciplina un papel estratégico en este terreno. Otra cuestión es que se decida a utilizarlo.

\section{BIBLIOGRAFÍA}

AGNEW, J. (2005): «Space: Place», en CLOKE, P. y JOHNSTON, R. (eds.) Spaces of Geographical Thought: Deconstructing Human Geography's Binaries. London. Sage, 81-96. ANHOLT, S. (2010): Places: identity, image and reputation. Basingstoke. Palgrave Macmillan. AOYAMA, Y., MURPHY, J.T. y HANSON, S. (2011) (Eds.): Key Concepts in Economic Geographies. London. Sage.

APPADURAI, A. (1996): Modernity at large: Cultural dimensions of globalization. Minneapolis. University of Minnesota Press.

ASHWORTH, G.J. y VOOGD, H. (1994): «Marketing and Place Promotion», en GOLD, J.R. y WARD, S.V. (Eds.) Place Promotion: The Use of Publicity and Marketing to Sell Towns and Regions. Chichester. Wiley, 39-52.

BACKHAUS, G. (2009): «The Problematic of Grounding the Significance of Symbolic Landscapes», en BACKAUS, G. y MURUNGI, J. (Eds.) Symbolic Landscapes. Berlin. Springer, 3-31.

BAUMAN, Z. (2007): Consuming life. Cambridge. Polity Press.

BECK, U., GIDDENS, A. y LASH, S. (1994): Reflexive modernization: Politics, tradition and aesthetics in the modern social order. Stanford. Stanford University Press.

BELL, S. (1999): Landscape: Pattern, Perception and Process. London. Spon. 
BERQUE, A. (1995): Les Raisons du Paisage, de la Chine Antique aus Environnements de Synthèse. Paris. Hazan.

CAMPELO, A. (2015): «Rethinking Sense of Place: Sense of One and Sense of Many», en KAVARATZIS, M., WARNABY, G. y ASHWORTH, G. (Eds.) Rethinking Place Branding. Comprehensive Brand Development for Cities and Regions. Berlin. Springer, 51-60.

CÀNOVES, G., PRAT, J.M. y BLANCO, A. (2016): «Turismo en España, más allá del sol y la playa. Evolución reciente y cambios en los destinos de litoral hacia un turismo cultural». Boletín de la Asociación de Geógrafos Españoles, nº 71, 431-454.

CASTORIADIS, C. (1985): La institución imaginada de la sociedad. Barcelona. Tusquets.

CHATZIDAKIS, A. (2014): "Athens as a Failed City for Consumption (In a World that Evaluates Everyone and Every Place by their Commodity Value) », en BREKKE, J.K., DALAKOGLOU, D., FILIPPIDIS, C. y VRADIS, A. (Eds.) Crisis-Scapes: Athens and Beyond. Athens. Economic \& Social Research Council and University of Sussex, 33-41.

CHENG, C.K. y KUO, H.Y. (2015): «Bonding to a new place never visited: Exploring the relationship between landscape elements and place bonding». Tourism Management, $\mathrm{n}^{\circ}$ 46, 546-560.

COSGROVE, D. (1984): Social Formation and Symbolic Landscape. London. Croom Helm.

COSGROVE, D. (1985): «Prospect, perspective and the evolution of the landscape idea». Transactions for the Institute of Bristish Geographers, $\mathrm{n}^{\circ}$ 10, 45-62.

COSGROVE, D. y DANIELS, S. (Eds.) (1988): The Iconography of Landscape. New York. Cambridge University Press.

CONSEJO DE EUROPA (2000): «Texto oficial de la Convención Europea de Paisaje». Disponible en: https://rm.coe.int/CoERMPublicCommonSearchServices/DisplayDCTMCon tent?documentId=09000016802f3fbd

DANIEL, T.C. (2001): «Whither scenic beauty? Visual landscape quality assessment in the 21st century». Landscape and Urban Planning, vol. 54 (1-4), 267-281.

DE BURGH-WOODMAN, H. y BRACE-GOVAN, J. (2010): «Vista, vision and visual consumption from the Age of Enlightenment». Marketing Theory, vol. 10 (2), 173-191.

DE UÑA, E. y VILLARINO, M. (2011): «Configuraciones de identidad en territorios del turismo. Condiciones generales en Galicia». Cuadernos de Turismo, n 27, 259-272.

DOMOSH, M. (2013) «Consumption and Landscape», en JOHNSON, N.C., SCHEIN, R.H., y WINDERS, J. (Eds.) The Wiley-Blackwell Companion to Cultural Geography. Chichester. John Wiley \& Sons, 198-208.

DUNCAN, J. y DUNCAN, N. (1988): «(Re)reading the landscape». Environment and Planning D: Society and Space, vol. 6 (2), 117-126.

GOODMAN, M.K., GOODMAN, D. y REDCLIFT, M. (2010): «Introduction: Situating Consumption, Space and Place», en GOODMAN, M.K., GOODMAN, D. y REDCLIFT, M. (Eds.) Consuming Space. Placing Consumption in Perspective. Aldershot. Ashgate, 1-40.

GOVERS, R. y GO, F.M. (2009): Place branding: Glocal, virtual and physical identities, constructed, imagined and experienced. Hampshire. Palgrave Macmillan.

GOVERS, R. (2011) : «From place marketing to place branding and back». Place Branding and Public Diplomacy, vol. 7 (4), 227-231. 
GREGORY, D. (2009): «Space», en GREGORY, D., JOHNSTON, R., PRATT, G., WATTS, M.J. y WHATMORE, S. (eds.) The Dictionary of Human Geography (5th Edition). Chichester. Wiley-Blackwell, 707-710.

HANKINSON, G. (2004): «Relational network brands: Towards a conceptual model of place brands». Journal of Vacation Marketing, vol.10 (2), 109-121.

HANSEN, A. y MACHIN D (2013): «Researching visual environmental communication». Environmental Communication: A Journal of Nature and Culture, vol. 7 (2), 151-168.

HARVEY, D. (1989): The condition of postmodernity: An enquiry into the origins of cultural change. Oxford. Blackwell.

HENDERSON, G. (2009): «Place», en GREGORY, D., JOHNSTON, R., PRATT, G., WATTS, M.J. y WHATMORE, S. (Eds.) The Dictionary of Human Geography (5th Edition). Chichester. Wiley-Blackwell, 539-541.

HIERNAUX, D. (2006): «Los centros históricos: ¿espacios posmodernos? (De choques de imaginarios y otros conflictos)», en LINDÓN, A. et al. (Eds.) Lugares e imaginarios en la metrópolis. Barcelona. Anthropos y Universidad Autónoma Metropolitana, 27-41.

JACKSON, P. (1989): Maps of Meaning: An Introduction to Cultural Geography. London. Routledge.

KAVARATZIS, M. (2005): «Place branding: A review of trends and conceptual models». The Marketing Review, vol. 5 (4), 329-342.

KAVARATZIS, M. y HATCH, M.J. (2013): «The Dynamics of Place Branding: An Identitybased Approach to Place Branding Theory». Marketing Theory, vol.13 (2), 69-86.

KONIGSBERG, I. (2004): Diccionario técnico Akal de cine. Madrid. Akal.

KOTLER, P. y GERTNER, D. (2002): «Country as brand, product, and beyond: A place marketing and brand management perspective». The Journal of Brand Management, vol. 9 (4), 249-261.

LEFEBVRE, H. (1991): The Production of Space. Oxford. Blackwell.

LASH, S. y URRY, J. (1994): Economies of signs and space. London. Sage.

LITTON, R.B. (1972): «Aesthetic dimensions of the landscape», en KRUTILLA, J.V. (Ed.) Natural Environments: Studies in Theoretical and Applied Analysis. Baltimore. Johns Hopkins University, 262-291.

LYNCH, K. (1960): The Image of the City. Cambridge, MA. MIT Press \& Harvard University Press.

MACCANNELL D., y MACCANNELL, J.F. (1982): The time of the sign: a semiotic interpretation of modern culture. Bloomington. Indiana University Press.

MACCANNELL, D. (1999): The Tourist: a new theory of the leisure class. Berkeley. University of California Press.

MANSVELT, J. (2010): «Geographies of consumption: engaging with absent presences». Progress in Human Geography, vol. 34 (2), 224-233.

MARUANI, T. y AMIT-COHEN, I. (2013): «Marketing landscapes: The use of landscape values in advertisements of development projects». Landscape and Urban Planning, $\mathrm{n}^{\mathrm{o}}$ 114, 92-101.

MASSEY, D. (2005): For Space. London. Sage.

MATLESS, D. (2003): «Gestures around the visual». Antipode, 35 (2), 222-226. 
MEDWAY, D. y WARNABY, G. (2008): «Alternative perspectives on marketing and the place brand». European Journal of Marketing, n 42 (5-6), 641-653.

MITCHELL, D. (2002): «Cultural landscapes: the dialectical landscape-recent landscape research in human geography». Progress in Human Geography, vol. 26 (3), 381-389.

MOYA, A. (2011): «The phenomenological experience of the visual landscape», en NIJHUIS, S., VAN LAMMEREN, R. y VAN DER HOEVEN, F. (Eds.) Exploring the visual landscape. Amsterdam. IOS Press, 57-71.

MULLINS, P., NATALIER, K., SMITH P. y SMEATON, B. (1999): «Cities and Consumption Spaces». Urban Affairs Review, $\mathrm{n}^{\circ} 35$ (1), 44-71.

MURAKAMI, D. y BALL, K. (2013): «Brandscapes of control? Surveillance, marketing and the co-construction of subjectivity and space in neo-liberal capitalism». Marketing Theory, vol. 13 (1), 47-67.

NOGUÉ, J. (2009): Entre paisajes. Barcelona. Àmbit.

NOGUÉ, J. y SAN EUGENIO, J. (2011): «La dimensión comunicativa del paisaje. Una propuesta teórica y aplicada». Revista de Geografía Norte Grande, nº 49, 25-43.

ODE, Å., TVEIT, M.S. y FRY, G. (2008): «Capturing Landscape Visual Character Using Indicators: Touching Base with Landscape Aesthetic Theory». Landscape Research, vol. (1), 89-117.

OLINS, W. (2003): On Brand. London. Thames \& Hudson.

OVERTON, J. (2010): «The consumption of space: Land, capital and place in the New Zealand wine industry». Geoforum, $\mathrm{n}^{\circ} 41$ (5), 752-762.

PIKE, A. (2009): «Geographies of brands and branding». Progress in Human Geography, vol. 33 (5), 619-645.

PIKE, A. (2013): «Economic Geographies of Brands and Branding». Economic Geography, vol. 89 (4), 317-339.

PORTER, N. (2013): «Single-minded, compelling, and unique: visual communications, landscape, and the calculated aesthetic of place branding». Environmental Communication: A Journal of Nature and Culture, vol. (2), 231-254.

PORTER, N. (2016): Landscape and Branding. The Promotion and Production of Place. Abingdon. Routledge.

RAKIĆ, T. y CHAMBERS, D. (2012): «Rethinking the consumption of places». Annals of Tourism Research, vol. 39 (3), 1612-1633.

ROSE, M. (2002): «Landscape and labyrinths». Geoforum, no 33 (4), 455-467.

SACK, R.D. (1992): Place, modernity, and the consumer's world: A relational framework for geographical analysis. Baltimore. John Hopkins University.

SAN EUGENIO, J. (2013): «Fundamentos conceptuales y teóricos para marcas de territorio». Boletín de la Asociación de Geógrafos Españoles, n $^{\circ}$ 62, 189-211.

SAN EUGENIO, J. y BARNIOL, M. (2015): «The relationship between rural branding and local development. A case study in the Catalonia's countryside: Territoris Serens (E1 Lluçanès)». Journal of Rural Studies, $\mathrm{n}^{\mathrm{o}}$ 37, 108-119.

SAUER, C.O. (1925): The Morphology of Landscape. Berkeley. University of California Press. SCHROEDER, J.E. (2002): Visual consumption. London. Routledge.

SCHROEDER, J.E. (2004): «Visual consumption in the image economy», en EKSTRÖM, K. y BREMBECK, H. (Eds.) Elusive Consumption. Oxford. Berg, 229-244. 
SCOTT, A.J. (2014): «Beyond the creative city: cognitive-cultural capitalism and the new urbanism». Regional Studies, vol. 48 (4), 565-578.

SOJA, E.W. (1989): Postmodern geographies: The reassertion of space in critical social theory. Londres y New York. Verso.

TOBIAS, S. y MÜLLER, P.M. (2013): «Can place branding support landscape conservation in city-regions? A case study from Switzerland». Land Use Policy, vol. 30 (1), 266-275.

TUAN, Y.F. (1974): Topophilia. Englewood Cliffs, NJ. Prentice-Hall.

TUAN, Y.F. (1979): «Thought and landscape. The eye and the Mind's Eye», en MEINIG, D.W. (Ed.) The interpretation of ordinary landscapes. New York. Oxford University Press, 89-102.

TVEIT, M., ODE, Å. y FRY, G. (2006): «Key concepts in a framework for analysing visual landscape character». Landscape Research, vol. 31 (3), 229-255.

URRY, J. (1995): Consuming places. London. Routledge.

URRY, J. (2002) The tourist gaze: Leisure and travel in contemporary societies $\left(2^{\text {nd }}\right.$ ed.). Londres. Sage.

WARD, S.V. y GOLD, J.R. (1994): Place promotion: The use of publicity and marketing to sell towns and regions. Chichester. Wiley.

WARNABY, G. (2009): «Towards a service-dominant place marketing logic». Marketing Theory, vol. 9 (4), 403-423.

WARNABY, G. y MEDWAY, D. (2013): «What about the "place” in place marketing?». Marketing Theory, vol. 13 (3), 345-363.

WYLIE, J. (2007) Landscape. Abingdon. Routledge. 